\title{
New Species of Anomochilus from Borneo (Squamata: Anomochilidae)
}

\author{
Indraneil Das, ${ }^{1,2}$ Maklarin LaKim, ${ }^{3}$ Kelvin K. P. Lim, ${ }^{4,5}$ and Tan HeOK Hui ${ }^{4}$ \\ ${ }^{1}$ Institute of Biodiversity and Environmental Conservation, Universiti Malaysia Sarawak, 94300, Kota Samarahan, \\ Sarawak, Malaysia; E-mail: idas@ibec.unimas.my \\ ${ }^{3}$ Zoology Unit, Sabah Parks, Gunung Kinabalu Park, Sabah, Malaysia; E-mail: maklarin@yahoo.com \\ ${ }^{4}$ Raffles Museum of Biodiversity Research, National University of Singapore, Lower Kent Ridge, Singapore 119260 \\ ${ }^{5}$ E-mail: dbslimkp@nus.edu.sg
}

\begin{abstract}
A new species of Anomochilus is described from Gunung Kinabalu Park, Sabah, Malaysia (Borneo). The new species is diagnosed from the only two other known species in the genus by the combination of the following character states: SVL to $509 \mathrm{~mm}$; an azygous parietofrontal; paravertebrals 269; transverse body rows $17: 19: 17$; midventrals 258-261; subcaudals 7-8; dorsum unpatterned dark brown, except for pale flecks, one scale wide, on paravertebral region; large pale blotches absent on dorsum; flanks without light line; and a pair of large pale blotches present on either side of venter. A dichotomous identification key to the three currently known species of Anomochilus is provided. With three species of Anomochilus known for Borneo, the island is the center of diversification of this genus of presumably fossorial and cryptozoic snakes.
\end{abstract}

The genus Anomalochilus was established by van Lidth de Jeude (1890) for Anomalochilus weberi van Lidth de Jeude, 1890 (type locality: "Sumatra: Kaju tanam" [ = Kajutanam, Sumatera Province, western Indonesia]). Berg (1901) showed that the generic name is preoccupied by Anomalochilus Blanchard, 1850: Coleoptera (Williams and Wallach, 1989), and provided the replacement name, Anomochilus. McDowell (1975) placed the genus under Cylindrophiidae, but more recently, it was allocated to the Anomochilidae (Cundall et al., 1993), with molecular data showing its relationships with some but not other members of the Cylindrophiidae, rendering the latter possibly paraphyletic (Gower et al., 2005). Smith (1940) described a second species, Anomochilus leonardi (type locality: "Sungei Ngeram, near Merapoh, N. Pahang, Malay Peninsula, at about 800 feet altitude"). A few additional specimens have since been reported from the Malay Peninsula (see Lim and Kamarudin, 1975; Tweedie, 1983; Abdul and Lim, 1993; Norsham, 2003). Both species have been reported from Borneo in recent checklists (e.g., Stuebing, 1991, 1994; Das, 2006): Brongersma and Helle (1951) recorded weberi from Kutai (Kalimantan Timur Province, Indonesia), while Stuebing and Goh (1993) mentioned the occurrence of leonardi from Sepilok Forest Reserve, Sandakan (Sabah, Malaysia), although the sole specimen these workers examined differed from those on Peninsular Malaysia in some aspects of its pholidosis. The

\footnotetext{
${ }^{2}$ Corresponding Author.
}

small sample size available until now (about 10 specimens for the two nominal species) has precluded the understanding of within-population variation and aspects of the biology of these poorly known, fossorial snakes.

Thus, two nominal species of Anomochilus are recognized in recent works (Cundall and Rossman, 1993; David and Vogel, 1996; Manthey and Grossmann, 1997; McDiarmid et al., 1999; Stuebing and Inger, 1999; Iskandar and Colijn, 2001), the members of which are exclusively Sundan in distribution, with records from Sumatra, Borneo, and peninsular Malaysia. The members of the genus are defined by the following suite of characters: head small, indistinct from neck; forehead covered with large scales that may be either symmetrical or show an azygous parietofrontal; nostril in a single nasal, which is in contact with Supralabial II; loreal and preocular absent; a single postocular; eye small; mental groove absent; body scales smooth; and tail short and conical (de Rooij, 1917; Tweedie, 1983; Manthey and Grossmann, 1997).

In this paper, we report on a population from montane regions of northern Borneo that does not fit the description of the two known species of Anomochilus, which is consequently described as new to science.

\section{Materials And Methods}

Historical material of both currently known species of Anomochilus was examined, including recent specimens referred to $A$. leonardi by Norsham (2003) and Stuebing and Goh (1993). See Appendix 1. 